\title{
EXTRACTOS DE REVISTAS
}

\section{EMBARAZO DESPUES DE HISTERECTOMIA SUBTOTAL}

\section{JAIME Garcia LOMbardero}

La lectura de la publicación de H. F. ZIPRICK e I. CRAWFORD en (Am. J. of Obst. a Gyn.) Febrero 1953, pág. 416, №̣ 2. Vol. 65, que lleva por título el del presente trabajo, nos mueve a someter a la consideración de los ginecólogos un caso igual en el que hemos seguido una conducta terapéutica diametralmente opuesta a la que han adoptado los referidos autores americanos.

Los A.A. hallaron una gestación de cuatro meses y medio en una enferma a la cual se le habia practicado con anterioridad una histerectomía subtotal. Pero ante el temor de una inminente rotura uterina en el futuro parto, decidieron provocarle el aborto medicamentoso mediante la pitocina. Ante el fracaso de este método, optaron por la intervención activa practicándole una laparotomía y extirpación del útero restante con el embarazo en curso. Expongamos ahora nuestro caso:

Enferma A.S.P., de treinta y siete años, casada hace un año. No partos ni abortos. Antecedentes sin interés. Se consulta por presentar menorragias y esterilidad. A la exploración nos encontramos con un útero miomatoso del tamaño y forma de una gestación de cinco meses aproximadamente. Ultima regla, quince dias antes de la consulta. Causa profundo disgusto a la enferma el suponer que, una vez operada, sus esperanzas de maternidad quedarían anuladas. Tratamos de convencerla - piadosamentede lo contrario, y se aviene a ser operada. Hemos de declarar ante todo que, según costumbre, trataríamos de dejar alguna porción de útero funcional con objeto de conservar la menstruación.

(1) Extractado de la Rev. Española de Obs. y Gin. Año XIII Tomo XV. No 85. Enero-Febrero de 1956. 
OPERACION.-Laparatomía media infraumbilical bordeando ombligo. A la vista del tumor apreciamos su morfología y relaciones con el útero. Tratábase de un mioma multilobulado, de asiento predominante intersticial, hallándose interesado por el proceso neoplásico la casi totalidad del cuerpo uterino. No obstante, se podía comprobar la existencia de una pequeña zona sobre istmo de consistencia normal. Previa la forcipresión, sección y ligadura de los pedículos uterinos (ligamentos redondos y úteroovárico, trompa y arteria uterina de ambos lados), seccionamos horizontalmente el cuerpo del útero en el límite de la zona supraistmica que por palpación apreciamos normal. Formamos un pedículo de cada lado e incluímos mediante sutura sus extremos en la exigua y restante cavidad uterina. Sutura de ambos labios de la sección por encima. Peritoneización. Cierre por planos. Alta a los once dias sin complicación alguna.

Doce días después de la operación se nos comunica -con gran satisfacción de la enferma- que ha tenido una escasa menstruación. Se repitió ésta periódicamente durante tres meses consecutivos. Cuatro meses después nos visita la enferma manifestándonos con disgusto que sus reglas habian cesado por completo. Contaba ya cuatro faltas menstruales y un estado general deprimido, ofreciendo una sintomatología imprecisa, pero que nos hacía recordar el cuadro que ofrecen muchas mujeres en los primeros meses de la gestación. Al efectuar la exploración nos hallamos con la sorpresa de una gestación de cuatri; meses que con.. firmamos al siguiente día mediante un Galli-Mainini positivo. El embarazo siguió su curso absolutamente normal. El día del parto la ingresamos en el Sanatorio - como simple medida preventiva - al iniciarse las primeras contracciones y a las diez horas siguiente dió a luz un feto vivo del sexo femenino de 3.330 gramos de peso. Alumbramiento sin incidencias. Alta a los seis días. En estas fechas (diciembre de 1945) cumple la niña siete meses. La madre se encuentra en perfecto estado con menstruaciones normales.

\section{COMENTARIOS}

Creemos prudente dejar a juicio del lector los comentarios sobre la distinta conducta observada en los dos casos objeto del parangón. Nos permitimos sólo dar a conocer los hechos escuetamente, y rogamos a los compañeros ginecólogos que tengan conocimiento de un suceso igual tengan a bien comúnicárnolo, bien 
REVISTA COLOMBIANA DE OBSTETRICIA Y GINECOLOGÍA

entendido - para evitar confusiones- que no se trata de embarazo después de miomectomía sino de embarazo después de histerectomía, lo que lleva consigo la sección y ligadura de las trompas.

\title{
ESTREPTOCINASA-ESTREPTODORNASA EN HIDROTUBACIO- NES EN EL TRATAMIENTO DE LA ESTERILIDAD POR OBSTRUCCION TUBARINA
}

\author{
Jorge D. Elias Costa y Pedro Guglielmone
}

Obst. Gin. Lat. Amer. XIV: 20. 1956.

Los autores presentan las experiencias realizadas en nueve pacientes estériles por obstrucción tubaria, empleando hidrotubaciones con Estreptocinasa y Estreptodornasa.

El método se basa en la acción de las referidas substancias sobre los exudados purulentos antiguos o recientes y con procesos fibrinosos leucocitarios y hematomas; persigue el restablecimiento de la permeabilidad tubaria eliminando por estos medios, los motivos que constituyeron dicha obstrucción, generalmente secuelas de procesos inflamatorios e infecciones intraluminales.

Los casos fueron escogidos previa una persuflación negativa. No fue utilizada la Histerosalpingografía para que la posible permeabilización de la trompa no fuese atribuída al Lipiodol. El número de Hidrotubaciones, practicadas en la segunda semana del ciclo, no pasó de cinco en cada ciclo y fue utilizada una dilución de Estreptocinasa-estreptodornasa (Varidasa) con 10, 15 o 20 cc. de Suero fisiológico o agua destilada. De los nueve casos presentados, en $4(4.4 \%)$ hubo resultado exitoso con embarazo posteriur en uno de ellos, en cuatro no se obtuvo permeabilización tubaria y uno no se pudo controlar. F. P. V. 